\title{
Bem Viver: Projeto U-tópico e De-colonial
}

Lacerda, Rosane Freire ${ }^{1}$

Feitosa, Saulo Ferreira ${ }^{2}$

\section{Resumo}

O presente artigo trata da concepção andina do "Bem Viver", tradução das expressões Kechwa "Sumak Kawsay" e Aymara "Suma Qamaña". Partindo dos sinais da atual crise civilizatória e ambiental provocada pelo capitalismo e seu suporte ideológico calcado no individualismo e no racionalismo, questiona-se a pretensa relação do "Bem Viver" com conceitos moderno-ocidentais como "desenvolvimento humano" e "qualidade de vida", e defende-se o termo como expressão de uma utopia andina baseada numa cosmologia e filosofia próprias, e nos processos de resistência indígena à colonialidade do poder.

Bem Viver. Colonialidade. Descolonialidade. Utopia indígena.

\begin{abstract}
o
El artículo aborda la concepción andina del "vivir bien", traducción de las expresiones Kechwa "Sumak Kawsay" y Aymara "Suma Qamaña". Dejando señales de actual crisis ambiental y de civilización causada por el capitalismo y su apoyo ideológico basado en el individualismo y racionalismo, cuestiona la supuesta relación del "buen vivir" con conceptos moderno-occidentales como "desarrollo humano" y "calidad de vida", y trata sobre el "buen vivir" como expresión de una utopía basada en la filosofía y Cosmología Andina y en los procesos de resistencia indígena a la colonialidade del poder.
\end{abstract}

Bien Vivir. Colonialidad. Decolonialidad. Utopía indígena.

\footnotetext{
${ }^{1}$ Doutora em Direito, Estado e Constituição pela UnB, professora adjunta do curso de Direito da Regional Jataí da UFG, Goiás, Brasil. Especialista em Direitos Indígenas e dos Refugiados, atua em Teoria do Estado; Pensamento Decolonial e Bioética e Direito.

2 Doutor em Bioética pela Universidade de Brasília (UnB), professor do curso de Medicina da UFPE/CAA, Pernambuco, Brasil, professor da Cátedra Unesco de Bioética da UnB, assessor do Conselho Indigenista Missionário (Cimi), membro-titular da Comissão Nacional de Política Indigenista (CNPI) do Ministério da Justiça
} 
Bien Vivir es, probablemente, la formulación más antigua en la resistencia indígena contra la Colonialidad del Poder.

Aníbal Quijano

Os países do Sul global abrigam uma grande diversidade étnico-racial, em temos de pluralidade de valores, saberes, modos de pensar, estilos de vida e projetos de futuro, tão diversos entre si quanto estranhos e antagônicos àqueles próprios da modernidade ocidental capitalista.

Estes valores e saberes indígenas têm sido historicamente identificados, pela mentalidade hegemônica do Norte, como incivilidade, primitivismo e atraso, uma atitude denunciada por autores latino-americanos contemporâneos, ligados à teoria crítica, como colonialidade do poder (QUIJANO, 1992; GROSFOGUEL, 2007; MIGNOLO, 2003), uma mentalidade e postura política típica da expansão colonial moderna e eurocêntrica, mantida viva e profundamente ativa após o fim do colonialismo.

Nas últimas décadas, com o avanço entre os povos indígenas na América Latina da consciência de sua sujeição a esta colonialidade no plano dos estados nacionais, várias expressões de opção descolonial foram ganhando visibilidade e força (QUIJANO, 2011; CASTRO-GÓMEZ; GROSFOGUEL, 2007; MIGNOLO, 2008).

Uma delas é dada pelos povos indígenas da região andina que afirmam, no conceito de Bem Viver, a possibilidade da vida fora dos parâmetros do bem-estar proclamados pela modernidade ocidental eurocêntrica e capitalista, ou seja, fora da lógica da colonialidade.

O presente artigo traz a questão do chamado Buen Vivir, tradução do conceito andino de Suma Qamaña ou Sumak Kawsay (nas línguas Aymara e kechwa, respectivamente), enquanto importante exemplo dos saberes dos povos indígenas, que se expressa tanto enquanto afirmação política da possibilidade de outros modos de vida, quanto como forma de resistência e enfrentamento à colonialidade moderna eurocêntrica que historicamente tem lhes imposto modos de vida estranhos e desconectados com sua realidade, valores e identidades. 


\section{Desenvolvimento Econômico Para Quê, Para Quem e a Que Custo?}

Uma das principais questões associadas à emergência, na América Latina, da ideia de Bem Viver, vem a partir dos debates em torno do chamado desenvolvimento econômico. O discurso do desenvolvimento econômico trazido como um fetiche pelo modelo neoliberal tem sido justificado pelo sistema como condição necessária para a promoção do conceito (ocidental) de bem-estar, cada vez mais baseado no consumo ilimitado de recursos naturais.

Ao analisar tal discurso, Pablo Dávalos (2008) identifica cinco importantes fissuras ou rupturas (cesuras) que afetam principalmente os povos do Sul global: a fragmentação e separação do ser humano em relação à natureza, herança do advento do modelo racional cartesiano; a ruptura com a ética, na medida da incompatibilidade natural desta com a ideia de desenvolvimento e crescimento econômico; a ruptura com a história e cultura própria dos povos, dada a preferência do capitalismo pela homogeneidade; a ruptura causada pela própria economia na medida em que o seu crescimento importa em mais exclusão e desigualdade, e, por último, a ruptura causada pela colonização epistêmica, que impede os povos de enxergarem alternativas ao sistema.

Alimentando-se da ideia da separação entre homem e natureza, o discurso do desenvolvimento se choca com a cosmologia indígena. Para esta, ser humano e natureza são indissociavelmente ligados, e a visão antropocêntrica responsável pela sua ruptura é incompreensível e problemática.

Medindo-se pelo racionalismo individualista e impulsionados pelo consumismo, os conceitos de desenvolvimento e crescimento econômico chocam-se também com as perspectivas éticas que mantém a coesão interna daqueles povos. Daí sua negativa a incorporar os valores e estilos de vida ocidentais, e sua resistência aos projetos governamentais desenvolvimentistas.

Também a história e as identidades culturais dos povos sofrem rupturas em razão do discurso do desenvolvimento e do crescimento, com os quais são igualmente incompatíveis: "El mundo liso y llano de Burguer King, de Nike, de Mc Donalds, de Coca Cola, de Wal-Mart, etc., es la apuesta por colonizar esa diversidad cultural e integrarlas al capitalismo" . (DÁVALOS, 2008.). 
Para o sistema as histórias e culturas destes povos só interessam na medida em que, pelo seu apelo exótico, podem ser convertidas em mercadorias de consumo, numa folclorização que as esvazia de sentido e as transforma em meras peças decorativas, despidas de identidades e propósitos próprios.

O mito neoliberal da erradicação da pobreza pelo crescimento econômico leva também a rupturas negativas para a vida dos povos do Sul global. Na medida em que se tem por foco o desenvolvimento e crescimento econômico, o âmbito político no qual repousam as causas da exploração e das relações verticalizadas de poder continua mantido, perpetuando a situação de subalternidade. Para os povos indígenas esta tem sido representada no aumento expressivo das pressões pela desterritorialização (ALMEIDA, 2009, p.103) e liberação de recursos naturais ao mercado internacional de commodities.

Por fim, a colonização epistêmica do desenvolvimento retira dos povos do Sul global a capacidade de enxergar saídas viáveis ao sistema. Ao apontar esta fissura, Dávalos repercute o conceito de colonialidade do poder desenvolvido por Quijano, que põe em destaque o fato de que, apesar do fim do colonialismo, "la relación entre la cultura europea (...), y las otras, sigue siendo una relación de dominación colonial (...), una colonización de las otras culturas (...), del imaginario de los dominados" (QUIJANO, 1992, p.61).

Diante dessa "colonização do imaginário", a capacidade do dominado de avaliar o mundo ao redor e imaginar algo diferente, é embotada pelos limites impostos pelos padrões de pensamento que orientam o capitalismo.

O imaginário e a capacidade de pensar alternativas ficam prejudicados. $\mathrm{O}$ sistema passa a ser visto como a única inexorável realidade e, as mazelas que traz consigo, um fardo inevitável (DAVALOS, 2008.).

Com isso as consequências da retórica do desenvolvimento, "su legado de destrucción ambiental, degradación humana, violencia social, colonización de las conciencias" (DAVALOS, 2008), são vistas como naturais e inevitáveis. 


\section{Superexploração de Recursos Naturais, Crise Climática}

A cada ano as Nações Unidas alertam para a relação entre superexploração dos recursos naturais, emissão de dióxido de carbono e mudanças climáticas no planeta. Em seu último relatório, o Intergovernmental Panel on Climate Change (IPCC) $)^{i}$ alertou que "a continuação das emissões de gases de efeito estufa" aumentará "a probabilidade de impactos severos, penetrantes e irreversíveis para as pessoas e os ecossistemas" (IPCC, 2014a).

No Brasil, o primeiro relatório do Painel Brasileiro de Mudanças Climáticas (PBMC) divulgado em janeiro de 2015 confirma denúncias de ambientalistas, povos indígenas e comunidades tradicionais, quanto aos impactos ambientais da pecuária extensiva e das monoculturas praticadas pelo agronegócio. Segundo ele, tais impactos, como o aumento da temperatura, já podem ser observados, como na região amazônica onde "a substituição de áreas naturais por pastagens contribui para um aquecimento de $1,5^{\circ} \mathrm{C}$ " (PBMC, 2015, p.328).

No processo "biopolítico" de privatização da vida, expande-se sobre as terras do Sul global o uso das sementes geneticamente modificadas. Entre seus efeitos nefastos, chama a atenção uma onda de suicídios de pequenos agricultores, na Índia, vítimas da Monsanto (TEIXEIRA, 2015.). Enquanto isso a água potável, inacessível a mais de 700 milhões de pessoas no planeta (OMS; UNICEF, 2014), é transformada em mercadoria através da privatização das companhias públicas de abastecimento, negócio lucrativo com retorno "estimado entre US $\$ 5$ e US $\$ 28$ por cada Dólar investido" (WWAP, 2015a.). A célebre "guerra del água" em Cochabamba, Bolívia no ano 2000, é até agora a expressão mais representativa da resistência dos povos do Sul global a este modelo.

Enquanto o IPCC calcula os limites da irreversibilidade do desequilíbrio ecológico e climático planetário (IPCC, 2014b), no Vaticano a gravidade da situação levou o Papa Francisco a dedicar ao tema a sua carta encíclica Laudato Si' (Louvado Sejas), "Sobre o cuidado da casa comum", onde apela por medidas capazes de salvar o futuro do planeta (LS, 14.).

Ao mesmo tempo, fugindo de extremos climáticos, de guerras, ou de péssimas condições de vida, milhares de pessoas deixam a cada ano o Sul global, num imenso fluxo misto que envolve refugiados, migrantes e "refugiados ambientais". 
Trata-se aqui de uma verdadeira crise civilizatória, onde a velha utopia liberal se mostra completamente obsoleta para as demandas de garantia da vida no planeta.

\section{Bem-Estar, Idh, Qualidade de Vida Ou "Mal-Viver"?}

À medida que aumenta o mal-estar com as consequências individuais e coletivas dos problemas relacionados ao estilo de vida, desigualdade socioeconômica e desequilíbrio ambiental, entram em voga conceitos de "viver melhor", "bemestar", "qualidade de vida", e "desenvolvimento humano", os três primeiros facilmente associados a dicas de saúde física e mental proporcionadas em conselhos médicos, orientações psicológicas, receitas culinárias, etc.

O termo bem-estar é fruto de uma construção da modernidade e como tal portador de uma perspectiva essencialmente individualista. Um viés que pode ser observado em quatro tendências analíticas (NOGUEIRA, 2002): a utilitarista, que reduz o conceito à ideia de utilidade; a que o reduz ao acesso a bens; a que o vê como satisfação das necessidades básicas humanas, e a que o vê como dependente das capacidades humanas para atingi-lo. Esta última tendência influenciou, a partir de proposta de Sen (1993), o conceito de desenvolvimento humano (PNUD, S/d.), fazendo surgir o Índice de Desenvolvimento Humano (IDH), que leva em conta níveis de renda, educação e saúde, substituindo o uso do Produto Interno Bruto (PIB) per capita, "que considera apenas a dimensão econômica do desenvolvimento" (PNUD, s/d.).

Recentemente a iniciativa privadaii lançou o "Índice de Progresso Social" (IPS), um conjunto mais amplo de indicadores baseado na satisfação de necessidades humanas básicas, melhoraria de qualidade de vida e pleno potencial de indivíduos e comunidades (DELOITTE, s/d.).

Os modelos de bem-estar e boa vida propagados pelo liberalismo burguês acabam tendo como referencial o inatingível estilo de vida e de consumo norteamericanos, que cobra seu preço em saúde mental. Pressões por se atingir os mesmos índices de produção e consumo registrados naquele país, frustração por não se conseguir atingi-lo, ou simplesmente o vazio de um estilo de vida consumista e individualista, aumentam ano a ano graves prejuízos para a saúde. 
Grande parte da população nos grandes centros urbanos tem problemas com o sono, em virtude de preocupações com dinheiro, segurança financeira e stress no trabalho (SÃO PAULO TIMES, 2015). Entre os graves problemas decorrentes aponta-se a depressão que atingiria "quase $7 \%$ da população mundial" (LUCENA; VERSOLATO, 2014.). Enquanto isso, a Organização Mundial de Saúde (OMS), informa que no mundo mais de 800 mil pessoas suicidam-se anualmente (OMS, 2014, p.11.). Apontando para o crescimento desta taxa no Brasil, um pesquisador da Escola Nacional de Saúde Pública vê "um processo muito grande de individualismo, de disputa, de competitividade e tudo tem a ver, estruturalmente, com as ideias de suicídio" (AFN, 2014.).

O estilo de vida moderno tem mais a ver com o que poderíamos chamar de malviver, para utilizarmos um termo trazido por Tortosa (2011). Um mal-viver marcado por pobreza e exploração, e pelo stress da competição e do consumo, que leva ao adoecimento físico e mental, depreda os recursos naturais do planeta e põe em risco a própria viabilidade da espécie humana.

\section{Um "beco sem saída”?}

Todo este quadro, longe de ser passageiro, agrava-se dia a dia e revela a incapacidade do atual modelo de sociedade para dar conta das demandas cada vez mais complexas e de efeitos colaterais cada vez mais perturbadores. Como afirma Edgard Lander, "Se trata nada menos que de una crisis civilizatoria, de la imposible continuidad del modelo industrialista y depredador basado em la lucha de los humanos contra la naturaleza" (LANDER, 2009, p.3).

Enquanto uma reação da sociedade parece distante, na indústria da música, o modelo consumista irreal e inatingível da "ostentação" é vendido com sucesso aos jovens, em sua maioria, negros de periferia. No crescente mercado da fé, fieis buscam bênçãos divinas traduzidas em prosperidade econômica, ou seja, mais bens de consumo. Reproduzindo a retórica hobbesiana, consumismo, individualismo e desigualdade parecem fazer parte da natureza das coisas, desmobilizando a sociedade no sentido de críticas e formulação de alternativas. Para Lander o problema está "en nuestras propias cabezas, en el pensamiento atado a la reproducción de lo existente, en la débil capacidad de imaginar otras 
formas de entender las cosas" (LANDER, 2009, p.33). Com isso, chama a atenção para a necessidade de se questionar a própria concepção do que seja riqueza, definida por instrumentais epistêmicos que atribuem esta qualidade apenas àquilo que pode ser transformado em mercadoria. Daí afirmar que "ya no nos sirven (...), naturalizan y convierten en inevitable lo existente. Son instrumentos de matriz colonial eurocéntrica" (LANDER, 2009, p.36-37.).

Também Pablo Dávalos (2011) insiste que o liberalismo e seu correspondente econômico, como ideologia hegemônica alicerçada no conceito politicamente ontológico de indivíduo, egoísta por natureza, vende bem através das teorias econômicas neoliberais, a falsa ideia de que a modernidade capitalista, com seus elementos intrínsecos de exploração e desigualdade, seria uma consequência natural e inexorável da natureza humana. Assim o liberalismo econômico se vê não como uma concepção teórica historicamente datada, mas como uma realidade ahistórica, atemporal e desvinculada de qualquer contexto sociocultural, passando a falsa ideia de que "assim sempre foi e assim será". Mas a simples existência dos povos indígenas, vivendo há séculos não apenas fora da lógica do sistema, mas a ele resistindo, já demonstraria a falsidade de tais pressupostos: "Su sola presencia da cuenta de que el discurso del crecimiento económico, del progreso humano, y de la ideología de los mercados que se equilibran, es ideológica" (DÁVALOS, 2011,p.27).

Dávalos aponta o Bem Viver como "a única possibilidade teórica" de uma crítica radical ao liberalismo. E o faz porque, enquanto o marxismo estaria enredado em fundamentos e critérios epistemológicos próprios da modernidade - ente os quais a visão dos povos indígenas como sociedades primitivas e sem história -, comungando assim dos mesmos pressupostos ideológicos e epistêmicos do liberalismo, o Sumak Kawsay incorporaria não somente "en una sola dinámica la crítica a la modernidad y al capitalismo", mas o faria "desde una visión diferente: aquella de la alteridad radical" (DÁVALOS, 2011, p.23).

Isso significa que a ruptura com o sistema do Mal viver que ruma para o colapso da vida no planeta, dependeria da superação não apenas do liberalismo econômico, mas também da própria modernidade ocidental, que tem como base 
a monoculturalidade eurocêntrica do mundo (DÁVALOS, 2011, p.27.). Mas o que seria, enfim, o chamado Bem Viver ou o Sumak Kawsay?

\section{4 "Bem Viver": um conceito polissêmico?}

Nos últimos anos o termo Bem Viver passou a ser mencionado em diversas publicações e veículos de comunicação como sinônimo de vida saudável. Ao mesmo tempo, é associado a projetos de desenvolvimento econômico pelos governos equatoriano e boliviano, como garantia de qualidade de vida para os mais pobres. Seriam estes os marcadores do Bem Viver proposto pelos povos andinos? Haveria uma equivalência entre tal conceito e viver melhor, bem-estar, qualidade de vida e desenvolvimento humano?

Observando os usos do termo após a sua introdução nas Constituições do Equador (2007) e Bolívia (2009), alguns estudiosos apontam no Bem Viver uma natureza polissêmica, ou seja, passível de diferentes concepções. HidalgoCapitán e Cubillo-Guevara (2014), por exemplo, identificam esta polissemia em seis "debates abiertos" que dividem marxistas, indígenas e pós-modernosiii. A pergunta a ser colocada é se se trataria realmente de uma polissemia ou de usos instrumentais do termo. Entendemos que a melhor forma de análise esteja na tentativa de compreensão de suas raízes ancestrais, rejeitando quaisquer formas de uso instrumental, contaminadas por bases epistêmicas coloniais. Isso significa considerar não apenas as suas origens, mas também os sentidos atribuídos pelos próprios indígenas na sua construção contemporânea.

Partilhamos do entendimento daqueles que consideram como primeiro registro sobre o Bem Viver a "Primer Nueva Crónica y Buen Gobierno", escrita pelo indígena Aymara Felipe Guamán Poma de Ayala (1611). Ele registrou a complexidade da antiga ordem social incaica, num exercício de "reconstrucción de la história desde los grupos sociales subalternizados" (FERNÁNDEZ, 2009, p.268). Como "ladino", ou seja, servidor subalterno da administração colonial espanhola no território da antiga civilização incaica, denunciou as injustiças e atrocidades do governo dos conquistadores. Ao mesmo tempo, reivindicou à Coroa espanhola, como medida de Bom Governo e de Bem Viver, a 
administração daqueles territórios pelos próprios indígenas, com base em seus valores e costumes, embora já sob a perspectiva cristã.

Como ladino Guamán Poma pôde viajar e ter contato direto com pessoas do povo e com antigos depositários dos saberes incaicos. Para Fernández (2009, p.270) foi esse contato com a realidade dos conquistados e a sua abertura ao ouvir não só as suas queixas, mas também as suas avaliações críticas desta realidade, que valeram ao autor de Nuevas Crónicas as condições para anunciar, pela primeira vez, a proposta do Bem Viver. E foi esta capacidade de ver e escutar os conquistados sob a perspectiva de um também conquistado, costurando seus saberes ancestrais à sua capacidade de resistência à ordem colonial, injusta e genocida, que deu a Guamán Poma a possibilidade de desenvolver aquilo que Mignolo (2007) denomina desobediência epistêmica: resgatou historicamente e valorizou os saberes e práticas da ordem social conquistada e, ao mesmo tempo, os projetou como horizonte de sentido na busca pela substituição da nova ordem injusta imposta pelo sistema colonial.

Ao longo dos séculos esta capacidade de desobediência epistêmica dos povos indígenas da região andina foi marcada por diversas formas de resistência contra as ordens colonial e republicana (LACERDA, 2014). Mas é a partir da década de 1970 e 1990, com o avanço do projeto neoliberal e suas novas formas de expropriação, esmagamento cultural e identitário e impactos sobre o meio ambiente, que essa forma de desobediência irá ganhar uma nova dimensão. Identificando tal projeto com um projeto de morte, e atuando organicamente no apoio aos movimentos indígenas na sua luta anti-neoliberal e decolonial, intelectuais indígenas, mantidos em situação de invisibilidade pelo sistema, conseguiram fazer retornar a concepção do Bem Viver, não como contraponto semântico àquele projeto de morte que aqui denominamos mal-viver, mas como um projeto de futuro fortemente ancorado em valores ancestrais e em sua experiência de resistência acumulada ao longo de cinco séculos de opressão.

Foi então em meio ao colapso do regime soviético e à decretação do "fim da história" pelos arautos do neoliberalismo (FUKUYAMA, 1992), que vozes indígenas historicamente ocultadas e silenciadas fizeram (re)surgir o Bem Viver como projeto de futuro alternativo ao sistema moderno-colonial-capitalista. 


\section{O Bem Viver como projeto u-tópico e de-colonial}

$\mathrm{Na}$ base das crises políticas e ambientais que têm levado caos e morte aos povos do Sul global, é clara a relação direta com a hegemonia dos paradigmas da modernidade capitalista e eurocentrada, que se impõem globalmente através da colonialidade do poder (QUIJANO, 1992). A ideia do indivíduo universal dotado de razão e liberdade como núcleo do sistema, trazida pela utopia liberalburguesa, entra em choque e se sobrepõe colonialmente às visões antissistêmicas dos vários povos indígenas e tradicionais ao redor do planeta, ancorados na perspectiva comunitária e plural de vida.

Ao defender a existência de uma "utopia andina", Ramiro Santamaría enfatiza o caráter transformador daquilo que denomina de "função utópica": nela "hay crítica, enfrentamiento con la realidad, desenmascaramiento de las ficciones que la sostienen, hace que la realidad sea insostenible" (SANTAMARÍA, 2015, p.149). E destaca que no Ocidente as utopias tiveram importante papel na transformação da realidade. Todas elas nasceram sob o signo da insatisfação com a ordem vigente (Topos ou status quo) e cumpriram importante papel no sentido de impulsionar os sujeitos sociais a novos horizontes de possibilidades, operando transformações naquela realidade.

Tendo a função de antecipar o futuro, o discurso utópico aposta no caráter realizável da utopia, o que o coloca sempre em rota de colisão com a defesa do Topos. Para os defensores da ordem estabelecida, "siempre la utopia será considerada irrealizable". Uma vez realizada, se transforma em Topos, e assim “habrá un grupo de personas que mantendrán su 'sueño' y otras que, cuando haya opresión, continuarán con la función utópica de buscar una sociedad mejor". Assim, "la utopia siempre emerge" (SANTAMARÍA, 2015, p.151.).

Conforme observa este mesmo autor - com base nos estudos de Josef Esterman (1998) -, os povos andinos desenvolveram não só uma filosofia própria como o seu próprio norte utópico. A utopia andina estaria fundada em dois elementos básicos: a noção de Pachamama - a chamada "mãe terra" -, e o conceito de Sumak Kawsay ou Suma Qamaña que designam o Bem Viver andino. Para a 
compreensão de tal conceito Santamaría utiliza quatro princípios da filosofia andina: relacionalidade, correspondência, complementaridade e reciprocidade.

O princípio da relacionalidade afirma que todos os seres estão ligados ontologicamente entre si e com as forças do universo, o que contraria a filosofia moderna ocidental que separa homem e natureza e divide os seres em categorias distintas. A relacionalidade rejeita a pretensão antropocêntrica do domínio do homem sobre a natureza, e a própria ideia ocidental do indivíduo como um ente ontologicamente completo, quase isolado. $\mathrm{O}$ indivíduo é compreendido como um ser relacional, fazendo parte de um todo que compreende a própria ordem cósmica, da qual tem a responsabilidade de cuidar. Já o princípio da correspondência revela a concepção de uma "correlación mútua y bidirecional", presente "en todo nivel y en todos los aspectos de la vida" (SANTAMARÍA, 2015, p.160). Trata-se de uma relação dual, ou seja, na qual cada elemento corresponde a outro que a ele se contrapõe, e que com ele interage numa interferência recíproca. Assim, cura e enfermidade, orgânico e inorgânico, vida e morte, (ESTERMAN, 1989) seriam correspondentes.

O dualismo presente no princípio da correspondência leva ao princípio da complementaridade, pelo qual nenhum ente prescinde da conexão com outro. Um dos exemplos de como opera o princípio da complementaridade é o do "chacha-warmi”, observado por Rita Segato em seus estudos sobre as relações de gênero, que analisa na perspectiva decolonial: "No mundo da modernidade não há dualidade, há binarismo. Enquanto na dualidade a relação é de complementaridade, a relação binária é suplementar, um termo suplementa o outro, e não o complementa" (SEGATO, 2012, p.122).

Por último, o princípio da reciprocidade. Segundo Santamaría (2015), ele representa para o pensamento andino uma espécie de "normatividade cósmica", que envolve a aplicação dos outros princípios (relacionalidade, correspondência, complementaridade) nas relações entre todos os entes e elementos. Assim, "EI principio de reciprocidad (...) también tiene que ver con las relaciones religiosas, atmosféricas, rituales, económicas y hasta con los difuntos; es vigente inclusive más allá de la vida" (ESTERMAN, 1978.). Trata-se de uma complexa teia 
relacionada com o processo de manutenção da harmonia entre todos os seres, que tem na "Chacana" (a "cruz Inca") o seu elemento mais simbólico.

Assim, o norte utópico do Bem Viver andino está ancorado filosófica e eticamente em princípios radicalmente distintos daqueles que predominam na filosofia moderna ocidental, fundada numa perspectiva lógico-racional, individualista, especista e antropocêntrica.

O Bem Viver parte de uma visão cósmica ou holística de mundo (ESTERMAN,1989), na qual todos os seres, animados ou inanimados, viventes e não viventes, estão ligados entre si numa relação de interação e de completude mútua, cujo equilíbrio necessita ser mantido. Na tradição andina do Bem viver os seres e elementos não humanos não foram criados para a satisfação das necessidades humanas. Não constituem "recursos naturais" cuja função é a de servirem à exploração econômica. Na lógica do Bem Viver, assim como não há estratificação entre os seres do cosmos, também não se concebe estratificação entre os próprios humanos. O Bem Viver não consiste, portanto, em acumular bens de consumo, mas em colaborar com a manutenção do equilíbrio cósmico. Esta concepção aponta para uma forma de organização social comunitária e intercultural, avessa à assimetria de poder, de gênero e de "raça" hegemonicamente presente no mundo moderno ocidental. Uma forma de organização social voltada não para a satisfação de desejos e necessidades individuais através do acúmulo de riquezas materiais e de poder, mas para a satisfação das necessidades coletivas a partir de relações harmônicas e respeitosas não apenas com os outros seres humanos, mas com todos os demais habitantes do planeta (animais, plantas, etc.).

Nessa perspectiva, o Bem Viver trabalha com a ideia de respeito à diversidade, o que leva ao conceito de interculturalidade. Aceitar e respeitar a diferença significa também aceitar a semelhança. A relação intercultural é a ferramenta que garante a equidade cultural, possibilitando os processos dialógicos para a construção de consensos. Para solucionar os conflitos se procura chegar a consensos. Procura-se aprofundar a democracia para que não haja submissão. Submeter a minoria à maioria não é viver bem (SUESS, 2010). A proposta implica assim em rupturas epistêmico-conceituais traduzidas em orientações 
éticas e princípios expressos em várias dimensões de justiça: social e econômica, democrático-participativa, inter-generacional e interpessoal, interracial e Interétnica, ambiental, transnacional, e justiça como imparcialidade.

Ideias de viver melhor, bem-estar (individual ou social), qualidade de vida, desenvolvimento e progresso humano são dependentes do modelo capitalista de acumulação e consumo, levando facilmente ao apelo do estilo de vida norteamericano, que leva ao consumismo, superexploração de recursos naturais, desequilíbrio ecológico e conformismo com as desigualdades.

Por tais razões a concepção andina de Bem Viver em nada se relaciona àquelas noções ocidentais e modernas, não corresponde, por exemplo, à lógica do viver melhor, pois, como afirmam Albó e Galindo, ao contrário, "se lo contrapone a 'vivir mejor', entendido en el sentido social de que unos cuantos viven mejor a costa de otros que siguen viviendo peor" (ALBÓ e GALINDO, 2011, p.10). Também não se reduz a simples modelo alternativo de desenvolvimento econômico: "traduz sumak kawsay, suma qamaña ou ñandereko, expressões que estão vinculadas a uma determinada concepção da natureza tão inclusiva que a humanidade guardaria com ela uma relação de dependência por filiação" (CLAVERO, 2012, p.124-5). Também não se pode considerar válida a sua instrumentalização pelo sistema econômico liberal, que o transforma em mercadoria de consumo, ou pelo aparato estatal socialista, quando busca legitimar em seu nome políticas desenvolvimentistas com base no extrativismo, gerador de imensos impactos na vida daqueles povos e do meio ambiente.

Entendemos que, de modo contrário, o Bem Viver é um norte u-tópico que aponta para a possibilidade de um modo de vida e de relacionamento com os outros seres, meio-ambiente e o próprio universo de modo radicalmente distinto daquele vendido pelo capitalismo. Em sua rejeição aos elementos centrais da utopia liberal-burguesa e do próprio sistema capitalista (individualismo, racionalismo, liberalismo, antropocentrismo, especismo, consumismo, etc.) a concepção andina do Bem Viver possui aquela "função utópica" (SANTAMARÍA, 2015) de crítica e enfrentamento desta realidade. Além disso, ao expressar valores, práticas e saberes que resistem a cinco séculos de dominação colonial, "no alienta solamente la herencia del pasado, sino todo el aprendizaje de la 
resistencia histórica de tan largo plazo" (QUIJANO, 2011, p.859), o que demonstra a sua capacidade de transformação possível, realizável.

A utopia liberal-burguesa, nascida como mecanismo de defesa dos interesses da burguesia em ascensão frente ao sistema estratificado do Ancient Règime, há tempos não demonstra mais capacidade para dar conta da complexidade das mazelas que gerou através de seu modelo econômico - o capitalismo. Por outro lado, conforme lembra Dávalos (2011, p.28), "fue como una estrategia de defensa al avance del capitalismo que las organizaciones indígenas de América Latina propusieron la noción del Sumak Kawsay'. Este emerge então como uma nova utopia que tem como propósito guiar as ações humanas de modo a erradicar as injustiças sociais e econômicas e ao mesmo tempo garantir a continuação da vida no planeta.

Trata-se também de uma concepção profundamente de-colonial. O Bem Viver (re)emerge do e no imaginário dos conquistados, dos excluídos, como uma proposta epistemicamente desobediente (MIGNOLO, 2007) à colonialidade do saber (LANDER, 2005). Funda-se em saberes e práticas não só contra hegemônicas, mas também antissistêmicas. Revela não a conformidade com a simples abertura de espaços para modos de vida distintos daqueles estimulados pelo sistema moderno-colonial capitalista, mas, de modo contrário, a perspectiva de que tais modos de vida só terão chance com o próprio fim deste sistema, a própria consolidação da decolonialidade do poderiv.

\section{Considerações finais}

Com base na perspectiva decolonial, assumimos aqui a concepção do Bem Viver não como bem-estar material, mas como utopia que emerge dos saberes ancestrais indígenas, especialmente através de determinados princípios da cosmovisão andina. Não se trata da reprodução ou cópia do modelo andino, mas de "ideia força" nele inspirada, e de projeto em construção. Um conceito aberto que poderá ser sempre ressignificado, acrescido e atualizado, mas nunca instrumentalizado por concepções vinculadas à modernidade-colonialidade.

Trata-se de alternativa concreta ao modelo neoliberal que submete a natureza aos interesses do capital, legitima a dominação dos países "centrais", do "Norte" 
global, sobre os ditos "periféricos", do "Sul" global, concentra riqueza nas mãos de poucos e amplia o fosso social que separa os ricos dos pobres.

O Bem Viver propõe uma mudança de paradigma a partir de uma ruptura epistemológica com o pensamento ocidental hegemônico. Diferentemente do capitalismo que impõe o capital como centro referencial e do socialismo que coloca o ser humano no centro, ele tem como referência central a vida de todos os seres do Planeta, onde a espécie humana é compreendida como parte da natureza, assim como as demais espécies.

\section{Referências}

AFN. Suicídio: pesquisadores comentam relatório da OMS, que apontou altos índices no mundo. Agência Fiocruz de Notícias. Rio de Janeiro, 12.Set.2014.Disponível em: < http://portal.fiocruz.br/pt-br/content/suicidio-brasil-e-8o-pais-das-americas-com-maiorindice $>$. Acesso: 18.Jul.2015.

ALBÓ, Xavier; GALINDO, Fernando. Del desarrollo rural al desarrollo buen vivir. In: Seminario Internacional "Desarrollo Rural y Economía Campesina Indígena", 2011, La Paz, Memoria del..., La Paz: CIPCA, 2011, p. 77-82.

ALMEIDA, Alfredo Wagner B. de. Agroestratégias e Desterritorialização: os direitos territoriais e étnicos na mira dos estrategistas dos agronegócios. In: ALMEIDA, Alfredo W. B. de; CARVALHO, Gustavo (Orgs.). O Plano IIRSA na visão da Sociedade Civil Pan-Amazônica. Belém: FASE: UFPA, 2009.

CASTRO-GÓMEZ, Santiago; GROSFOGUEL, Ramón (Eds.). El Giro Decolonial. Reflexiones para una diversidad epistémica más allá del capitalismo global. Bogotá: Siglo del Hombre Editores; Universidad Central, Instituto de Estudios Sociales Contemporáneos y Pontificia Universidad Javeriana, Instituto Pensar, 2007.

CLAVERO, Bartolomé. Estado Plurinacional: Aproximação a um Novo Paradigma Constitucional Americano. In: BALDI, Cesar Augusto (Coord.) Aprender desde o Sul: Novas constitucionalidades, Pluralismo Jurídico e Plurinacionalidade. Aprendendo desde o Sul. Belo Horizonte: Fórum, 2015. pp.111-131.

DÁVALOS, Pablo. Comentário: EI Sumak Kawsay (Buen Vivir) y la crítica a la teoría económica como ideología. Polémika. Revista Cuatrimestral del Instituto de Economía de la Universidad San Francisco. 2011 Quito, Junio 2011.

DÁVALOS, Pablo. El "Sumak Kawsay" o el "Buen vivir" y las cesuras del desarrollo. Alai, América Latina en Movimiento. Quito, 06.May.2008. Disponível em: < http://www.alainet.org/es/active/23920 >. Acesso: 23 Jun.2015.

DELLOITE (s/d). O que é? Disponível em: <http://www2.deloitte.com/br/pt/ pages/about-deloitte/articles/indice-progresso-social.html>. Acesso: 07.jul.2015. ESTERMAN, Joseph. Filosofía Andina, Estudio intercultural de la sabiduría autóctona andina. Quito: Abya Yala, 1989. 
ESTERMAN, Joseph. Filosofía Andina. Sabiduría indígena para un mundo nuevo. 2 ed., La Paz: ISEAT, 2006.

FERNÁNDEZ, Carolina Ortiz. Felipe Guaman Poma de Ayala, Clorinda Matto de Turner, Trinidad Henríquez y la teoría crítica - sus legados a la teoría social contemporánea. Yuyaykusun. Revista del Departamento Académico de Humanidades de la Universidad Ricardo Palma. Lima, Perú. Época II, no2, Dic.2009, 263-284.

FRANCISCO, Papa. Laudato Si'. Carta Encíclica do Santo Padre Francisco sobre o cuidado da casa comum. São Paulo: Paulus Editora; Edições Loyola, 2015.

FUKUYAMA, Francis. The End of History and the Last Man. New York: The Free Press, 1992.

HIDALGO-CAPITÁN, Antonio Luis; CUBILLO-GUEVARA, Ana Patrícia (2014). Seis debates abiertos sobre el Sumak Kawsay. Íconos, Revista de Ciencias Sociales n.․․ 48, Quito, Enero.2014, p. 25-40.

IPCC. Climate Change 2014. Synthesis Report. Disponível em: <https://www.ipcc.ch/news_and_events/docs/ar5/ar5_syr_headlines_en.pdf >. Acesso: 15.Ago.2015.

IPCC Cambio Climático 2014. Impactos, adaptación y vulnerabilidad. Resumen para responsables de políticas. Disponível em: <http://www.ipcc.ch/ pdf/assessmentreport/ar5/wg2/ar5_wgll_spm_es.pdf > Acesso: 15.Ago.2015.

LACERDA, Rosane Freire "Volveré, y Seré Millones": Contribuições Descoloniais dos Movimentos Indígenas Latino Americanos para a Superação do Mito do Estado-Nação. 2 v. Tese (Doutorado em Direito) - Universidade de Brasília, Brasília, 2014.

LANDER, Edgardo. Hacia otra noción de riqueza. In: ACOSTA, Alberto; MARTÍNEZ, Esperanza (Comp.). El Buen Vivir: Una vía para el Desarrollo. Quito: Ediciones AbyaYala, 2009; pp.31-37.

LANDER, Edgardo (Org.). A colonialidade do saber: eurocentrismo e ciências sociais. Perspectivas latinoamericanas. Buenos Aires: CLACSO, 2005. Disponivel em: < http://bibliotecavirtual.clacso.org.ar/>. Acesso: Jun. 2012.

LUCENA, Rodolfo; VERSOLATO, Mariana. Depressão já é a doença mais incapacitante, afirma OMS. Folha de São Paulo. São Paulo - SP, 17.Dez.2014. Disponível em: http://www1.folha.uol.com.br/equilibrioesaude/ 2014/12/1563458depressao-ja-e-a-doenca-mais-incapacitante-afirma-a-oms.shtml >. Acesso: 17.Ago.2015.

MIGNOLO, Walter. Historias Locales, Diseños Globales: Colonialidad, Conocimientos Subalternos y Pensamiento Fronterizo. Madrid: Akal, 2003.

MIGNOLO, Walter. Epistemic disobedience: the de-colonial option and the meaning of identity in politics. Gragoatá. Publicação do Programa de Pós-Graduação em Letras da Universidade Federal Fluminense, n.ํำ 22 (jan./jun. 2007). Niterói: EdUFF, 2007. 
MIGNOLO, Walter. La opción de-colonial: desprendimiento y apertura. Un manifiesto y un caso. Tabula Rasa. Bogotá - Colombia, n. $-8: 243-281$, enero-junio 2008.

NACIONES UNIDAS. Agua, cambio climático y desastres. Nota de la Secretaría

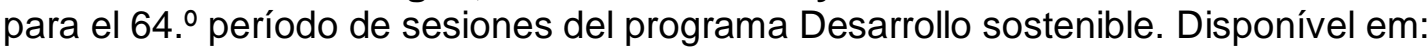
<http://www.un.org/es/comun/docs/?symbol=A/64/695>. Acesso: 05.Ago.2015.

NOGUEIRA, Vera Maria Ribeiro. Bem-Estar, Bem-Estar Social ou Qualidade de Vida: a Reconstrução de um Conceito. Semina: Ciências Humanas e Sociais, Londrina, v.23, p.107-122, set. 2002.

NUSSBAUN, Martha; SEN, Amartya. The quality of life. Oxford: Clarendon Press, 1993.

OMS (2014). Preventing Suicide, a global imperative. Disponível em: < http://apps.who.int/iris/bitstream/10665/131056/1/9789241564779eng.pdf?ua=1\&ua=1 >. Acesso 17.Jul.2015.

OMS; UNICEF (2014). Progresos en materia de agua potable y saneamiento: informe de actualización 2014. Disponível em: <http://apps.who.int/iris/bits tream/10665/164016/1/9789243507248_spa.pdf?ua=1\&ua=1 >. Acesso: 05.Ago.2015.

PNUD (s/d). Desenvolvimento Humano e IDH. A abordagem de desenvolvimento humano olha para as oportunidades e capacidades das pessoas. Disponível em: < http://www.pnud.org.br/IDH/RDH.aspx? indiceAccordion=0\&li=li_RDH >. Acesso: 07.Jul.2015.

QUIJANO, Aníbal . "Bien Vivir": Entre el "desarrollo" y la des/colonialidad del poder. In: QUIJANO, Aníbal. Cuestiones y Horizontes. De la Dependencia HistóricoEstructural a la Colonialidad/ Descolonialidad del Poder. Buenos Aires: Clacso, 2014, pp.847-859.

QUIJANO Aníbal Colonialidad y modernidad-racionalidad. In: PALERMO, Zulma; QUINTERO, Pablo (compiladores). Aníbal Quijano. Textos de Fundación. Buenos Aires: Ediciones del Signo, 2014; pp.60-70.

SÃO PAULO TIMES (2015). Estresse no trabalho e problemas financeiros afetam a saúde do sono dos brasileiros. São Paulo, março de 2015. Disponível em: http://www.saopaulotimes.com.br/sp/estresse-no-trabalho-e-problemas-financeirosafetam-a-saude-do-sono-dos-brasileiros/ >. Acesso: 02.Ago.2015.

SANTAMARÍA, Ramiro Ávila (2015). La Utopia Andina. In: BALDI, Cesar Augusto (Coord.) Aprender desde o Sul: Novas constitucionalidades, Pluralismo Jurídico e Plurinacionalidade. Aprendendo desde o Sul. Belo Horizonte: Fórum, 2015. pp.141-178.

SEGATO, Rita Laura (2012). Gênero e colonialidade: em busca de chaves de leitura e de um vocabulário estratégico descolonial. E-cadernos CES [Online], 18, 2012: 106131. Disponível em: <http://eces.revues.org/1533 >. Acesso: 05.Jul.2015. 
SUESS, Paulo (2010). Viver Bem - Sumak Kawsay - Reino de Deus. Disponível em: < http://www.missiologia.org.br/cms/UserFiles/cms_artigos_pdf_83.pdf >. Acesso: 15.Abr.2013.

TEIXEIRA, Marcos (2015). La leyenda negra de Monsanto: ¿Está detrás de los suicidios de agricultores en la India? Miércoles, 27 de mayo del 2015. Disponível em: < http://noticias.lainformacion.com/mundo/la-leyenda-negra-de-monsanto-estadetras-de-los-suicidios-de-agricultores-en-la-india_7RCvsG BFnDxSvckOQGLN46/ >. Acesso: 18.Jun.2015.

\section{TORTOSA, José María (2011). Maldesarrollo y Mal Vivir. Pobreza y Violencia a Escala Mundial. Quito: Ediciones Abya Yala, 2011.}

WWAP (2015a). Relatório Mundial das Nações Unidas sobre Desenvolvimento dos Recursos Hídricos. Água para um Mundo Sustentável. Sumário executivo. Disponível em: < http://www.unesco.org/new/fileadmin/MULTIMEDIA/HQ/SC/ images/WWDR2015ExecutiveSummary_POR_web.pdf >. Acesso: 03.Jul.2015.

WWAP (2015b). Agua Para un Mundo Sostenible. Datos y Cifras. Disponível em:<http://unesdoc.unesco.org/images/0023/002322/232272por.pdf >. Acesso: 17.Jul.2015.

\footnotetext{
i Organismo criado em 1988 pela Assembleia Geral das Nações Unidas.

ii Elaborado pelo instituto norte-americano Social Progress Imperative, pela Harvard Business School, Delloitte Touche Tohmatsu e Skoll Foundation.

iii Alguns "neomarxistas" identificam o "Bem viver" como proposta socialista e estatista, portanto, de cunho moderno, sinônimo de bem-estar material e modelo de desenvolvimento alternativo ao capitalismo. Outros, porém, o veriam como proposta retrógrada e contra-revolucionária. Para os indígenas o "Bem Viver" vem dos saberes originários, da cosmovisão andina, portanto nem moderna nem pós-moderna, estaria carregado de espiritualidade e seria avesso à ideia de desenvolvimento. Já os "pós-modernos" e os ambientalistas o veriam como um projeto em construção, pós-moderno, aberto a contribuições de lógicas e valores de culturas diversas e expressão da possibilidade de formas alternativas de desenvolvimento.
}

iv Para tanto, Quijano defende a realização de práticas sociais baseadas em valores antissistêmicos, como "la igualdad social de individuos heterogeneos y diversos"; a eliminação das desigualdades fundadas em diferenças e identidades; a vinculação dos indivíduos a grupos e identidades como expressão não de imposições mas das "decisiones libres y autónomas de indivíduos libres y autónomos"; a reciprocidade na organização do trabalho e na distribuição dos produtos; "la redistribución igualitária de los recursos y productos, tangíbles e intangibles, del mundo, entre la población mundial"; a associação "comunal de la población mundial, a escala local, regional o globalmente", e a "co-responsabilidad en las relaciones con los demás seres vivos y otras entidades del planeta o del universo entero" (QUIJANO, 2011, p.857). 